\title{
The Patient Enablement Instrument-French version in a family practice setting: a reliability study
}

\author{
Catherine Hudon ${ }^{1,2^{*}}$, Martin Fortin ${ }^{1,2}$, Francis Rossignol ${ }^{3}$, Susie Bernier ${ }^{2}$ and Marie-Eve Poitras ${ }^{2}$
}

\begin{abstract}
Background: Patient enablement can be defined as the extent to which a patient is capable of understanding and coping with his or her health issues. This concept is linked to a number of health outcomes such as selfmanagement of chronic diseases and quality of life. The Patient Enablement Instrument (PEI) was designed to measure this concept after a medical consultation. The instrument, in its original form and its translations into several languages, has proven to be reliable and valid. The purpose of this study was to evaluate the reliability of the French version of the PEI (PEI-FV) in a family practice setting.

Methods: One hundred and ten participants were recruited in a family medicine clinic in the Saguenay region of Quebec (Canada). The PEI-Fv was completed twice, immediately after consultation with a physician (T1) and 2 weeks after the consultation (T2). The internal consistency of the tool was assessed with Cronbach's $\alpha$ and testretest reliability by intraclass correlation coefficient.

Results: The mean score for the PEI-Fv was $5.06 \pm 3.97$ (95\% confidence interval [Cl]: 4.30-5.81) at T1 and $4.63 \pm$ 3.90 (95\% Cl: 3.82-5.44) at T2. Cronbach's $\alpha$ was high at T1 $\left(\alpha_{1}=0.93 ; 95 \% \mathrm{Cl}: 0.91-0.95\right)$ and T2 $\left(\alpha_{2}=0.93 ; 95 \%\right.$ Cl: 0.91-0.95). The intraclass correlation coefficient was 0.62 ( $95 \% \mathrm{Cl}: 0.48-0.74)$, indicating a moderate test-retest reliability.

Conclusions: The internal consistency of the PEI-Fv is excellent. Test-retest reliability was moderate to good. Testretest reliability should be examined in further studies at a less than 2-week interval to reduce maturation bias. This instrument can be used to measure enablement after consultation in a French-speaking family practice setting.
\end{abstract}

\section{Background}

Health promotion can be defined as the "process of enabling people to increase control over, and to improve, their health" [1]. Promoting health is at the heart of the encounter between patients and primary healthcare providers. Howie et al. [2,3] proposed that the concept of enablement represents the extent to which a patient feels enabled after a medical consultation. They advocated that this concept be used as a measure of the quality of the consultation, rather than a patient's satisfaction with it. They hypothesized that it may represent an intermediary outcome that promotes coping or self-efficacy that is linked to health and

\footnotetext{
* Correspondence: catherine.hudon@usherbrooke.ca

'Département de médecine de famille, Université de Sherbrooke, Québec, Canada

Full list of author information is available at the end of the article
}

behaviour change. Two different studies conducted in Scotland $[4,5]$ found that the impact of enablement on daily living at first consultation was highly predictive of positive changes in main complaint and well-being at 1 and 3 months, after controlling for the number of consultations among patients. In the study done by Bikker et al. [4], enablement at 3 months was predictive of changes in main complaint and well-being at 12 months. Significant positive correlations were also found between patient enablement and change in quality of life at 4 weeks and 12 weeks for patients suffering from asthma in general practices in the UK $[6,7]$.

The Patient Enablement Instrument (PEI), which was developed to measure patient enablement after a medical consultation in primary care, showed good psychometric properties [2,3]. To date, English [2,3], Polish [8], Croatian [9], and Chinese [10] versions of the PEI have 
been developed. The purpose of this study was to evaluate the reliability of a French version of the PEI (PEI-Fv) in a French-speaking family practice setting.

\section{Methods}

\section{Study design and setting}

We carried out a reliability study of the PEI-Fv with patients attending the family medicine clinic of a regional health centre (Centre de santé et de services sociaux de Chicoutimi) in Saguenay, Québec, Canada, using a waiting-room survey immediately after their consultation (T1) with a health professional, followed by a questionnaire sent by mail 2 weeks after the consultation (T2).

\section{Participants and sampling}

To be included in the study, a participant had to be 18 years of age or older, a regular patient of the family medicine clinic for over a year, able to read and respond to a questionnaire in French, and attending the clinic to see a physician or resident (other than the principal investigator). Patients were excluded if they had an unstable acute condition or a decompensated psychiatric condition or if they came to the clinic without a prior appointment (walk-ins) or were unable to provide informed consent. We also excluded patients who were pregnant because this condition requires special followup and is not a typical encounter.

In this clinical setting, patients mainly consult with physicians about issues with their chronic disease and care. In 2005, a study by Fortin et al. [11] found that overall, 9 of 10 patients in similar clinics had more than 1 chronic condition.

\section{Data collection}

We recruited a convenience sample of patients from the waiting room of the family medicine unit between July 6 and July 16 2010. The clinic's reception staff informed each patient that a research assistant would contact them in the waiting room and gave each adult patient a yellow card to flag them as possible participants. One of 2 trained research assistants approached all potentially admissible patients. The research assistant first asked for permission to speak with the patient and then proceeded to explain the nature, objective, and procedures of the project and to review the consent form and verify the patient's eligibility to enter the study. Patients were invited to ask any questions they had. If patients agreed to participate in the study and signed a consent form, the research assistant then explained how to complete the questionnaires (the PEI-Fv and sociodemographic questions documenting age, sex, education, family income, and marital status). The patient completed the self-administered questionnaires immediately after his or her consultation with the health professional (T1). After completing the questionnaires, patients handed them to the research assistant, who stored them in a secure file.

Two weeks after the initial consultation (T2), patients received the PEI-Fv by mail with a pre-addressed, prestamped envelope so that they could return it once they had completed it. We adapted Dillman's method [12] to optimize responses. Two weeks later, we sent a reminder postcard to all participants who had not returned the T2 questionnaire. One week after this reminder, we contacted participants by telephone to remind them once again about returning in the completed T2 questionnaire. If the participant asked, we sent another copy of the T2 questionnaire by mail, and as a last resort, we offered to help them complete it over the telephone.

\section{Patient Enablement Instrument}

The PEI (Figure 1) is composed of 6 questions, on a 3point scale ranging from 0 to 2, corresponding to "Same or less," "Better/More," and "Much better/Much more," respectively. Results for each questionnaire may vary between 0 and 12 points (the sum of scores for each item); a score of 12 indicates that the patient experienced maximum enablement. Internal consistency of the original English version was reported as excellent (Cronbach's $\alpha=0.93$ ) [3]. The Chinese version showed a good test-retest reliability of 0.75 , as calculated by the intra-class correlation coefficient (ICC) [10]. The rank correlation score calculated with the Consultation Satisfaction Questionnaire was $0.48(\mathrm{P}<0.01)[2,3]$.

The rigorous translation process involved several bilingual members of the research team taking particular care to preserve the subtle meaning of items, while preserving the cultural context. First, a bilingual member of the research team translated the original version into French. A panel of bilingual team members composed of researchers from medical and nursing disciplines examined both versions and made revisions to further adapt the questionnaire into Quebec French. The translated version (PEI-Fv) was then submitted to the panel once again.

We estimated that the sample size required to calculate the ICC with $5 \%$ precision and a power of $80 \%$ with an ICC $>0.60$ would be $>50$ patients [13]. Calculations done according to Dillman's method [12] suggest a sample size of 100 participants.

\section{Analysis}

We described the sample using mean \pm standard deviation (SD) for continuous variables such as age and patient enablement, and proportions for categorical variables (sex, marital status, education, family income).

We calculated the internal consistency for the PEI-Fv using Cronbach's $\alpha$ with a 95\% confidence interval (CI) 


Suite à votre visite médicale
récente, vous sentez-vous...
(As a result of your visit to the doctor today,
you feel you are ...)
capable de faire face à la vie
(able to cope with life?)
capable de comprendre vos
problèmes de santé
(able to understand your illness?)
capable de faire face à vos
problèmes de santé
(able to cope with your illness?)
capable de vous maintenir en
bonne santé
(able to keep yourself health?)

\section{BEAUCOUP PLUS}

(Much better)

\section{COMME AVANT LA VISITE OU MOINS \\ (Same or less) \\ PLUS}

\section{confiant par rapport à votre état de santé \\ (confident about your health?) \\ capable de vous aider vous- même \\ (able to help yourself?)}

(able to keep yourself health?

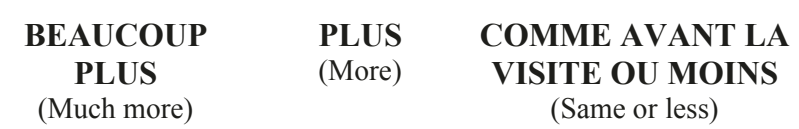

and the test-retest reliability by determining the ICC (95\% CI) between the 2 administrations of the questionnaire (PEI-Fv). We used the SPSS version 16.0 software for all analyses.

This study was approved by the ethics committee of the Centre de santé et de services sociaux de Chicoutimi (Québec, Canada).

\section{Results}

The research assistants approached a total of 129 potentially admissible patients. Of these, 112 (86.8\%) agreed to participate in the study; only $2(1.8 \%)$ of these participants did not return the completed questionnaire after consultation at $\mathrm{T} 1$.

Table 1 summarizes participants' characteristics: mean age was $59.1 \pm 16.2$. Most subjects were female (67/110, $60.9 \%), 86.2 \%(94 / 109)$ of participants had at least an $8^{\text {th }}$ grade education, $74 \%(77 / 104)$ had an income $\geq$ CAN $\$ 20,000$ and $57.8 \%(63 / 109)$ were married or lived with a partner. At T2, $90(81.8 \%)$ of the 110 participants returned their completed PEI-Fv. Patients with $\geq 1$ missing value on the patient enablement scale were excluded from the analysis: 2 patients were excluded from the analysis of PEI-Fv at T1 and 2 were excluded at T2.

The mean $( \pm \mathrm{SD})$ score for the PEI-Fv was $5.06(95 \%$ CI: $4.30-5.81 \pm 3.97)$ at $\mathrm{T} 1$ and 4.63 (95\% CI: 3.82-5.44 $\pm 3.90)$ at $\mathrm{T} 2$. The French instrument showed excellent internal consistency: the Cronbach $\alpha$ coefficient was 0.93 (95\% CI: 0.91-0.95) at T1 and 0.93 (95\% CI: 0.91$0.95)$ at T2. The ICC for PEI-Fv measures at T1 and T2 was 0.62 (95\% CI: 0.48-0.74).

\section{Discussion}

This is the first report of the reliability of a French version of the PEI. We were able to confirm an excellent internal consistency (Cronbach $\alpha$ coefficient $=0.93$ ), as described in previous studies $[2,3,6,8,10,14]$. The testretest reliability was moderate to good $(\mathrm{ICC}=0.62)$ 
Table 1 Participant characteristics $(n=110)$

\begin{tabular}{|c|c|c|}
\hline Characteristic & Number $(n=110)$ & $\begin{array}{l}\text { Percentage } \\
\text { (\%) }\end{array}$ \\
\hline $\begin{array}{l}\text { Mean age } \\
\text { Sex }\end{array}$ & \multicolumn{2}{|c|}{$59.1 \pm 16.2$} \\
\hline Male & 43 & 39.1 \\
\hline Female & 67 & 60.9 \\
\hline \multicolumn{3}{|l|}{ Education level completed } \\
\hline Grade 1-7 & 15 & 13.6 \\
\hline Grade 8-12 & 35 & 31.8 \\
\hline $\begin{array}{c}\text { College or post-secondary } \\
\text { school }\end{array}$ & 33 & 30.0 \\
\hline University & 26 & 23.6 \\
\hline Missing data/no response & 1 & 0.9 \\
\hline \multicolumn{3}{|l|}{ Family revenue (CAN\$) } \\
\hline$<10,000$ & 11 & 10.0 \\
\hline $10,000-19,999$ & 16 & 14.5 \\
\hline $20,000-29,999$ & 9 & 8.2 \\
\hline $30,000-39,999$ & 22 & 20.0 \\
\hline $40,000-49,999$ & 12 & 10.9 \\
\hline$\geq 50,000$ & 34 & 30.9 \\
\hline Missing data/no response & 6 & 5.5 \\
\hline \multicolumn{3}{|l|}{ Marital status } \\
\hline Married/living with partner & 63 & 57.3 \\
\hline Separated/divorced & 13 & 11.8 \\
\hline Widowed & 17 & 15.5 \\
\hline Single & 16 & 14.5 \\
\hline Missing data/no response & 1 & 0.9 \\
\hline
\end{tabular}

[15]. The only other data available for comparison are from the Chinese validation [10] that reports an ICC of 0.75 (95\% CI not provided) for a retest done 2-3 weeks after the first completion of the questionnaire. We planned on estimating the test-retest reliability in our study at 2 weeks to compare our results with those of the Chinese study. However, in the end, $27 \%$ of our sample completed the PEI-Fv T2 > 3 weeks after T1. Therefore, our weaker result could be explained by the longer delay between the completion of the PEI-Fv at $\mathrm{T} 1$ and at $\mathrm{T} 2$.

We observed that mean enablement at T2 was lower than that at T1. Lam et al. [10] also observed a decrease in mean patient enablement at T2 (4.65 at baseline and 4.22 at follow-up). The level of enablement may be maximal immediately after consultation. The difference between measures after 2 weeks could be explained by a change in the enablement level and may not be due to a difference in measure. However, we did not any identify studies documenting the evolution of the level of enablement over time after a medical consultation. Further studies should measure test-retest reliability after a shorter delay ( 3 or 4 days, for example). More research could also document the evolution of the level of enablement over time after a medical consultation.
In the United Kingdom, a survey of 25,994 adults done by Howie et al. [16] reported a mean PEI score of 3.1 (95\% CI: 3.1-3.1). In another study [17] of patient enablement in a population of patients undergoing acupuncture $(\mathrm{n}=52)$ throughout the United Kingdom, mean patient enablement was 3.62 (95\% CI: 2.89-4.76). A Scottish study [5] of 323 patients reported a mean PEI score of 3.65 (95\% CI not provided). The study [4] of 187 new outpatients at a Glasgow homeopathic hospital reports a mean PEI score of 3.7 (95\% CI: 3.2-4.2). Finally, in another study [18] conducted by Mercer and Watt with 3,044 patients in Scotland, mean patient enablement sores were $4.0 \pm 3.8$ and $3.9 \pm 3.5$ for patients from most deprived areas and least deprived areas, respectively. Results from the studies conducted in the United Kingdom in large populations are quite constant. Results from a study in Poland [8] that used a Polish version of the instrument present comparable results: mean patient enablement was 3.65 (95\% CI: $3.51-3.79)$ in a pilot study of 2,289 patients and $4.0(95 \%$ CI not given) in a study of 7,924 adult consultations.

The mean score for the PEI-Fv was 5.06 (95\% CI: 4.30-5.81). Our results are comparable to the results obtained for a Chinese-speaking population of 152 adults: 4.65 (95\% CI: 4.21-5.10) [10]. A much higher PEI score was obtained for a Croatian population of 5,527 patients $\geq 18$ years of age: the mean enablement score was 6.6 (95\% CI not provided) [9].

The differences in patient enablement observed in these studies may be the result of cultural differences, as Howie et al. discuss [16]. On the other hand, in comparison with the studies conducted in the United Kingdom $[2,3,5-7,16,17]$, the size of the current study's sample, as well as that of the Chinese sample [10], although sufficient to obtain adequate power for the objectives of the study, was relatively limited to be able to generalize a mean patient enablement score to that for a French or Chinese population. Further studies in a French-speaking setting, should measure patient enablement after consultation with larger samples. Finally, the mean score on the PEI and the length of the consultation may be linked to continuity of care [5]; however, we do not have data to examine this issue.

\section{Study limits}

The main limitation of our study was that some patients returned their completed questionnaires more than 2 weeks after their consultation, which may have introduced a maturation bias and negatively affected the testretest reliability of the PEI-Fv. A second limitation is that our results may not be applicable to patients on the lower end of the socioeconomic status scale because very few of the participants in our study fell into this category. In addition, our small sample size does not 
allow us to extrapolate the level of patient enablement to other or larger French-speaking populations; however, it did allow us to attain the objectives of our study. Notwithstanding these limits, our results confirm the reliability of our PEI-Fv.

\section{Conclusions}

The internal consistency of our PEI-Fv was excellent. Its test-retest reliability was moderate to good. The instrument can be used to measure enablement after consultation in a French-speaking family practice setting. The test-retest reliability should be examined in further studies at shorter intervals $(<2$ weeks) to reduce maturation bias. The evolution of the level of enablement over time should also be examined.

\section{List of abbreviations used}

PEl: Patient Enablement Instrument; PEl-Fv: French version of the PEl; $\mathrm{Cl}$ : confidence interval; ICC: intra-class correlation coefficient; SD: standard deviation.

\section{Acknowledgements}

MF is funded by the Canadian Institutes for Health Research (Chaire de recherche appliquée des IRSC sur les services et politiques de santé en maladies chroniques en soins de première ligne - Instituts de recherche en santé du Canada, Institut des services et politiques de santé, Fondation canadienne de recherche sur les services de santé et Centre de santé et de services sociaux de Chicoutimi). FR received a scholarship from the Canadian Institutes for Health Research for his participation in the research project as a research intern. We thank Sharon Nancekivell, medical editor, for revising this paper.

\section{Author details}

'Département de médecine de famille, Université de Sherbrooke, Québec, Canada. ${ }^{2}$ Centre de santé et de services sociaux de Chicoutimi, Québec, Canada. ${ }^{3}$ Faculté de médecine et des sciences de la santé, Université de Sherbrooke, Québec, Canada.

\section{Authors' contributions}

$\mathrm{CH}$ conceived and designed the study with MF and MEP. CH and SB drafted the manuscript. MF, MEP, and FR participated in the critical review of the manuscript. All authors gave their final approval of the version of the manuscript submitted for publication.

\section{Competing interests}

The authors declare that they have no competing interests.

Received: 23 February 2011 Accepted: 7 July 2011

Published: 7 July 2011

\section{References}

1. World Health Organization. Ottawa Charter for Health Promotion. [http:// www.who.int/hpr/NPH/docs/ottawa_charter_hp.pdf].

2. Howie JG, Heaney DJ, Maxwell M: Measuring quality in general practice. Pilot study of needs, process and outcome measure. Occasional Paper. J R Coll Gen Pract 1997, 75:i-xii, 1-32.

3. Howie JG, Heaney DJ, Maxwell M, Walker JJ: A comparison of a Patient Enablement Instrument (PEI) against two established satisfaction scales as an outcome measure of primary care consultations. Fam Pract 1998, 15:165-171.

4. Bikker A, Mercer SW, Reilly D: A pilot prospective study on the consultation and relational empathy, patient enablement, and health changes over 12 months in patients going to the Glasgow Homoeopathic Hospital. The Journal of Alternative and Complementary Medicine 2005, 11:591-600.
5. Mercer SW, Neumann M, Wirtz M, Fitzpatrick B, Vojt G: General practictioner empathy, patient enablement, and patient-reported outcomes in primary care in an area of high socio-economic deprivation in Scotland-A pilot prospective study using structural equation modeling. Patient Education and Counseling 2008, 73:240-245.

6. Haughney J, Cotton P, Rosen JP, Rosen JP, Morrison K, Price D: The use of a modification of the Patient Enablement Instrument in asthma. Prim Care Respir J 2007, 16:89-92.

7. Ind PW, Haughney J, Price D, Rosen JP, Kennelly J: Adjustable and fixed dosing with budesonide/formoterol via a single inhaler in asthma patients:the ASSURE study. Respiratory Medicine 2004, 98:464-475.

8. Pawlikowska TR, Nowak PR, Szumilo-Grzesik W, Walker JJ: Primary care reform: a pilot study to test the evaluative potential of the Patient Enablement Instrument in Poland. Fam Pract 2002, 19:197-201.

9. Ozvacic Adzic Z, Katic M, Kern J, Lazic D, Cerovecki Nekic V, Soldo D: Patient, physician, and practice characteristics related to patient enablement in general practice in Croatia: cross-sectional survey study. Croat Med J 2008, 49:813-823.

10. Lam CLK, Yuen NYK, Mercer SW, Wong W: A pilot study on the validity and reliability of the Patient Enablement Instrument (PEI) in a Chinese population. Family Practice 2010, 27:395-403.

11. Fortin M, Bravo G, Hudon C, Vanasse A, Lapointe L: Prevalence of multimorbidity among adults seen in family practice. Ann Fam Med 2005, 3:223-228.

12. Dillman DA: Mail and Internet Surveys The tailored design method. 2 edition New York: John Wiley \& Sons, Inc; 2000.

13. Donner A, Eliasziw M: Sample size requirements for reliability studies. Statistics in medicine 1987, 6:441-448.

14. Pawlikowska T, Walker J, Nowak P, Szumilo-Grzesik W: Patient involvement in assessing consultation quality: a quantitative study of the patient enablement instrument in Poland. Health Expectations 2009, 13:13-23.

15. Sneeuw KC, Aaronson NK, Sprangers MA, Detmar SB, Wever LD, Schornagel JH: Comparison of patient and proxy EORTC QLQ-C30 ratings in assessing the quality of life of cancer patients. J Clin Epidemiol 1998, 51:617-631.

16. Howie J, Heaney D, Maxwell M, Walker J, Freeman G, Rai H: Quality at general practice consultations: cross sectional survey. British Medical Journal 1999, 319:738-743.

17. Price S, Mercer SW, MacPherson H: Practitioner empathy, patient enablement and health outcomes: a prospective study of acupuncture patients. Patient Education \& Counseling 2006, 63:239-245.

18. Mercer SW, Watt GC: The inverse care law: clinical primary care encounters in deprived and affluent areas of Scotland. Annals of Family Medicine 2007, 5:503-510

Pre-publication history

The pre-publication history for this paper can be accessed here: http://www.biomedcentral.com/1471-2296/12/71/prepub

doi:10.1186/1471-2296-12-71

Cite this article as: Hudon et al:: The Patient Enablement InstrumentFrench version in a family practice setting: a reliability study. BMC Family Practice 2011 12:71.

\section{Submit your next manuscript to BioMed Central and take full advantage of:}

- Convenient online submission

- Thorough peer review

- No space constraints or color figure charges

- Immediate publication on acceptance

- Inclusion in PubMed, CAS, Scopus and Google Scholar

- Research which is freely available for redistribution 